\title{
INFLUENCIA DE LA EDUCACIÓN UNIVERSITARIA EN LA FORMACIÓN DE LA CULTURA TRIBUTARIA DEL CONTADOR PÚBLICO
}

\section{INFLUENCE OF UNIVERSITY EDUCATION ON THE FORMATION OF THE TAX CULTURE OF THE PUBLIC ACCOUNTANT}

\author{
William Alberto Pirela Espina \\ Investigador Independiente. Venezuela \\ williampirela@gmail.com
}

Fecha de recepción: 15/03/2021 - Fecha de aprobación: 18/03/2021

DOI: https://doi.org/10.36995/.visiondefuturo.2021.26.01.001.es

\section{RESUMEN}

Este trabajo tuvo como objetivo analizar la influencia de la educación universitaria en la formación de la cultura tributaria del contador público; donde la revisión bibliográfica estuvo dirigida a autores destacados en el área tales como: Matteucci (1995), Vizcaíno (2001), Robles (2002), Guaiquirima (2004), Brasvlasky (2005), Gómez (2008) y Coetzee y Oberholzer (2009), entre otros. Siendo una investigación bajo una metodología documental, un diseño bibliográfico puro, en la cual la recolección de la información se llevó a cabo a través de la técnica de observación documental. Se concluyó que la estructura curricular en la formación universitaria del contador público debe incluir programas de enseñanza orientados a fortalecer valores ciudadanos; siendo importante una relación combinada entre los órganos de la Administración Tributaria, la empresa privada y las instituciones universitarias para que de forma conjunta contribuyan con la generación de cultura tributaria en los ciudadanos. El futuro profesional tiene la oportunidad para consolidar su compromiso con el desarrollo del país, corrigiendo conductas arraigadas de evasión fiscal que se han hecho presente para escaparse de los deberes con el Estado; siendo el contador público agente multiplicador para el fortalecimiento de la cultura tributaria dentro de las organizaciones y la comunidad.

PALABRAS CLAVES: Cultura tributaria; Educación tributaria; Tributos.

\section{ABSTRACT}

The objective of this work was to analyze the influence of university education in the formation of the tax culture of the public accountant; where the bibliographic review was directed to prominent authors in the area such as: Matteucci (1995), Vizcaíno (2001), Robles (2002), Guaiquirima (2004), Brasvlasky (2005), Gómez (2008) and Coetzee and Oberholzer (2009), among others. Being an investigation under a documentary methodology, a pure bibliographic design, in which the collection of information was carried out through the

\footnotetext{
“Visión de Futuro" Año 19, Volumen No 26 N 1, Enero - Junio 2022 - Pág 1 - 21 URL de la Revista: http://visiondefuturo.fce.unam.edu.ar/index.php/visiondefuturo/index URL del Documento: https://visiondefuturo.fce.unam.edu.ar/index.php/visiondefuturo/issue/view/22 ISSN 1668 - 8708 - Versión en Línea E-mail: revistacientifica@fce.unam.edu.ar

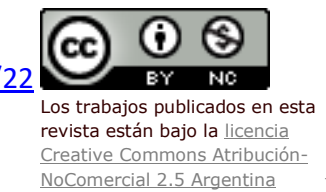


documentary observation technique. It was concluded that the curricular structure in the university training of the public accountant should include teaching programs oriented to strengthen citizenship values; being important a combined relationship between the bodies of the Tax Administration, private companies and university institutions so that together they contribute to the generation of tax culture in citizens. The future professional has the opportunity to consolidate their commitment to the development of the country, correcting deep-rooted behaviors of tax evasion that have been present to escape from duties to the State; being the public accountant multiplying agent for the strengthening of the tax culture within the organizations and the community.

KEY WORDS: Tax culture; Tax Education; Tributes.

\section{INTRODUCCIÓN}

La gran mayoría de las constituciones de los países del mundo señalan la obligatoriedad que tienen los ciudadanos en colaborar con la satisfacción de las cargas públicas del Estado a través del pago de los tributos. Esta colaboración no ha tenido mucha aceptación por parte de los contribuyentes, quienes buscan la asesoría del profesional de la contaduría pública con la finalidad de pagar la menor cantidad por concepto de tributos a través de la evasión y elusión fiscal.

A lo largo de la historia, los sujetos pasivos de la obligación tributaria sustancial siempre han tenido poca disposición para cumplir con este deber constitucional; demostrando un bajo nivel de cultura tributaria que se ve reflejado en los niveles de recaudación.

Ahora bien, para Velarde (2006), la conducta del ser humano puede ser modificada para transformar aspectos indeseables en productivos y aceptados para la sociedad; en virtud de lo cual se hace necesario inducir la conducta del ciudadano para que adopte la decisión de cumplir voluntariamente con sus obligaciones tributarias.

En este sentido, es necesario profundizar en la relación que debe darse entre el ciudadano y el Estado, a fin de generar una cultura que incida en su forma de concebir el cumplimiento de las obligaciones tributarias como un deber primordial acorde con los valores de una sociedad fundamentado en la supremacía del bien común.

Al respecto, Velarde (2006), afirma que desarrollar dicha cultura no es una tarea fácil, pues requiere de una convergencia de políticas de control con aquellas de carácter educativo; ante lo cual es imprescindible fomentar la cultura tributaria en los futuros contribuyentes, comenzando desde la educción universitaria; lo cual puede concebirse como

\footnotetext{
"Visión de Futuro" Año 19, Volumen N²6 N 1, Enero - Junio 2022 - Pág 1 - 21

URL de la Revista: http://visiondefuturo.fce.unam.edu.ar/index.php/visiondefuturo/index

URL del Documento: https://visiondefuturo.fce.unam.edu.ar/index.php/visiondefuturo/issue/view/22

ISSN 1668 - 8708 - Versión en Línea

E-mail: revistacientifica@fce.unam.edu.ar
} 
una solución tendiente a disminuir la evasión fiscal originada como consecuencia del bajo nivel de cultura tributaria en la población.

Por lo tanto, se hace necesario fomentar la cultura tributaria desde la temprana edad escolar, donde cada estudiante tenga la oportunidad de recibir y disertar sobre los valores y el compromiso que tiene como ciudadano en coadyuvar al Estado con las cargas públicas; y así poder corregir conductas arraigadas de evasión fiscal que se han hecho presentes continuamente en un número significativo de individuos para escaparse de los deberes tributarios.

Indudablemente, que la educación universitaria juega un papel fundamental en el profesional de la contaduría pública quien está llamado a ser agente multiplicador en su comunidad y en su ámbito profesional como pieza fundamental para el fomento de la cultura tributaria.

En virtud de esto, se hace necesario que las universidades incluyan programas de enseñanza en cultura tributaria para fortalecer los valores ciudadanos en los estudiantes, quienes serán los futuros contribuyentes; pero no sólo fomentar el conocimiento, sino también llevar a cabo práctica de ética fiscal en su futuro entorno profesional.

Si bien es cierto que los gobiernos de los países tienen la imperiosa necesidad de redimensionar las fuentes de ingresos, planteándose una mejora en la recaudación tributaria interna y la reducción de la evasión fiscal, se hace necesario cambiar la visión acerca del contribuyente e incentivar la cultura tributaria para que de forma voluntaria colaboren a solventar las necesidades de financiamiento de los gastos públicos.

Por ende, la cultura tributaria debe sustentarse en valores que tiendan al bien común, y desde el sistema educativo universitario, se debe tratar de concientizar a los profesores y estudiantes en la práctica constante de estos valores; haciéndose necesario que todos los ciudadanos fortalezcan su cultura tributaria y así puedan comprender que los tributos son recursos que recauda el Estado en su carácter de administrador, pero en realidad serán retribuidos a la comunidad en bienes y servicios públicos para mejorar su calidad de vida.

Sobre este particular, existen posturas teóricas que afirman que los niveles de cultura tributaria ocurren ante gobiernos que se destacan por la poca transparencia en el manejo de los recursos públicos, a esto se añade el posible incumplimiento del Código de Ética del Contador Público, para lo cual se aborda el impacto económico que ocasiona para todo país y los compromisos que deben cumplir los contadores ante la sociedad, bajo una perspectiva de la moral y de la ética.

\footnotetext{
"Visión de Futuro" Año 19, Volumen N²6 N 1, Enero - Junio 2022 - Pág 1 - 21

URL de la Revista: http://visiondefuturo.fce.unam.edu.ar/index.php/visiondefuturo/index

URL del Documento: https://visiondefuturo.fce.unam.edu.ar/index.php/visiondefuturo/issue/view/22

ISSN 1668 - 8708 - Versión en Línea

E-mail: revistacientifica@fce.unam.edu.ar
} 
Partiendo de estas consideraciones, el objetivo principal planteado en esta investigación consistió en analizar la influencia de la Educación Universitaria en la formación de la cultura tributaria del contador público.

Por otra parte, en muchas investigaciones es común que se aplique la metodología del meta-análisis como una herramienta importante para darle respuesta a una problemática planteada. Un meta-análisis implica una síntesis cuantitativa de la evidencia acumulada sobre una pregunta de investigación previamente definida; cuya respuesta se basará en la información contenida en los estudios previamente publicados (estudios primarios).

Para Botella y Sánchez-Meca (2015), el meta-análisis es una metodología para el análisis cuantitativo de revisiones de la literatura científica sobre una pregunta específica; una forma de valorar la calidad de un meta-análisis por parte del investigador es fijarse en la medida que sea preciso, objetivo y replicable. Estas características del meta-análisis le permiten al investigador obtener una estimación combinada del tamaño del efecto y evaluar la heterogeneidad observada en un campo de estudio; para ayudarlo a formular nuevas hipótesis que incorporan el papel de variables que no se habían tenido en cuenta hasta el momento.

Sin embargo, esta metodología presenta debilidades como son el problema de la heterogeneidad (amenaza real a la validez de las conclusiones del investigador) y el sesgo de publicación (mayor probabilidad de publicación para los estudios significativos).

Con base a lo planteado, este trabajo de investigación no estuvo basado en el metaanálisis de la cultura tributaria del contador público, sino que fue fundamentado en una revisión sistemática de la documental existente sobre el tema, de esta forma el investigador identificó y evaluó estudios del mismo tipo y con un objetivo común, como fue analizar la influencia de la Educación Universitaria en la formación de una cultura tributaria en el contador público

Razón por la cual, la investigación se realizó bajo una metodología de tipo documental, con un diseño bibliográfico puro, definido por De Pelekais, Finol; Neuman y Belloso (2007), como el proceso sistemático en la búsqueda de información, selección, lectura, registro, organización, descripción e interpretación de datos extraídos de fuentes documentales existentes en torno a un problema, a fin de encontrar respuesta a las interrogantes planteadas en cualquier área del conocimiento.

La revisión bibliográfica se efectuó al consultar las bases de datos electrónicas internacionales tales como Dialnet, Jstore, Redalyc, Scielo y Google Académico; de donde se extrajo información pertinente, entre los años 1990 a 2020; mediante la aplicación de la técnica observación documental, la cual, según Abreu (2016), consiste en un proceso

\footnotetext{
"Visión de Futuro" Año 19, Volumen No 26 N 1, Enero - Junio 2022 - Pág 1 - 21

URL de la Revista: http://visiondefuturo.fce.unam.edu.ar/index.php/visiondefuturo/index

URL del Documento: https://visiondefuturo.fce.unam.edu.ar/index.php/visiondefuturo/issue/view/22

ISSN 1668 - 8708 - Versión en Línea

E-mail: revistacientifica@fce.unam.edu.ar
} 
operativo para obtener y registrar de forma organizada la información presente en libros, revistas científicas, diarios, informes científicos, artículos publicados, entre otros.

En cada base de datos se seleccionaron seis (6) artículos con los cuales se creó una hoja en Excel, detallando los siguientes campos: datos, problema de investigación, objetivos, resultados y conclusiones. Luego se agruparon en dos ejes temáticos: la educación universitaria del contador público y la formación de una cultura tributaria, posteriormente se realizó un análisis de cada uno identificando lo más importante y relevante. Para concluir se determinaron las similitudes, las concordancias y las contradicciones entre los autores para finalmente argumentar en relación a la situación identificada.

Mediante el estudio se construyó un Estado del Arte en el cual se analizó la influencia de la Educación Universitaria en la formación de una cultura tributaria en el contador público. Para el efecto se exploró en las bases de datos citadas, focalizándose en los temas investigados para realizar un análisis pormenorizado del tema.

Así mismo, en aras de crear conocimiento se consultaron los autores pioneros en cultura tributaria, cuyos postulados aún se encuentran vigentes, tales como: Matteucci (1995), Vizcaíno (2001), Robles (2002), Guaiquirima (2004), Brasvlasky (2005), Gómez (2008) y Coetzee y Oberholzer (2009), entre otros.

\section{DESARROLLO}

El Estado es el responsable de la búsqueda del bien común de la sociedad, sin embargo, para ellos necesita que los ciudadanos contribuyan con el pago de los tributos para poder reinvertirlos en beneficio de la colectividad, convirtiéndose en un deber moral.

Para Vizcaíno (2001), estas obligaciones del Estado y los ciudadanos, suponen una inequívoca concepción del hombre como ser social y no como mero sujeto individual desconectado de la sociedad. Los tributos son la cuota de colaboración que todo ciudadano debe pagar por los beneficios que recibe del Estado y por la corresponsabilidad que debe ejercitar en relación al bien común. Sin embargo, para que el Estado cumpla su finalidad principal en relación con los tributos, son necesarias ciertas condiciones:

- el sistema impositivo sea justo.

- tenga la infraestructura material adecuada para que la recaudación pueda ser llevada a cabo a todos los que deben pagar, evitando, al máximo, la evasión.

- Los usos que haga el Estado sean efectivamente para el bien común.

Indudablemente, para que el Estado pueda cumplir con su obligación constitucional de velar por el bien común y proporcionar a la población los servicios básicos que ésta

\footnotetext{
"Visión de Futuro" Año 19, Volumen No 26 N 1, Enero - Junio 2022 - Pág 1 - 21

URL de la Revista: http://visiondefuturo.fce.unam.edu.ar/index.php/visiondefuturo/index

URL del Documento: https://visiondefuturo.fce.unam.edu.ar/index.php/visiondefuturo/issue/view/22

ISSN 1668 - 8708 - Versión en Línea

E-mail: revistacientifica@fce.unam.edu.ar
} 
requiere, necesita de recursos cuya principal fuente son los tributos pagados por los contribuyentes. Su pago puede ser canalizado por el Estado utilizando su poder coercitivo contenido en las leyes o apelando a la razón del ciudadano, la cual se manifiesta a través de una cultura tributaria con bases sólidas, lo que evidencia la estrecha relación que existe entre el pago de los tributos y el nivel de cultura tributaria de los ciudadanos.

Es de resaltar que, a nivel universitario se han planteado propuestas para incluir en la formación del futuro profesional aspectos que le permitan ayudar a elevar el nivel de cultura tributaria; planteando estrategias pedagógicas dirigidas a fomentar la cultura tributaria en los estudiantes.

Explica Robles (2002), que los estudiantes poseen un bajo conocimiento sobre los aspectos tributarios, por lo cual propone incluir a los programas educativos aquellos aspectos importantes de la legislación tributaria vigente, como lo son: tributo, clases de tributos, sujetos tributarios, la relación jurídica-tributaria, la obligación jurídica-tributaria, entre otros; para inculcar a los estudiantes una conciencia cívica y tributaria y lograr el objetivo de la Administración Tributaria que es modificar la conducta del contribuyente.

Para cualquier profesional, la universidad representa el lugar en el que aprenden el conjunto de saberes que le permitirán iniciarse en el ejercicio de una profesión con eficiencia, que le permitirá avanzar en los conocimientos propios de un ámbito del saber, de forma y manera tal que pueda emprender la investigación, especialización y profundización de los mismos. Sin embargo, no resulta tan obvio que la universidad sea el lugar en el que se aprenden principios éticos y ciudadanos.

Por consiguiente, en el actual contexto sociocultural, el entorno universitario es un espacio de aprendizaje, tanto de carácter profesional, cultural, humano, y, por ende, ético y moral. En este sentido, se debe considerar como un error de percepción desaprovechar esta función, ya que es un deber promover la potencia pedagógica de la universidad con relación al aprendizaje y formación de dichos valores en los estudiantes, toman en cuenta que dicha institución tiene voluntad de servicio público.

En este ámbito, la universidad tiene una función ética cuya dimensión la podemos identificar en la sociedad actual, en los siguientes aspectos:

- formación deontológica relativa al ejercicio de las diferentes profesiones,

- formación ciudadana y cívica de sus estudiantes; y

- formación humana, personal y social que contribuya a la excelencia ética y moral de los futuros profesionales

Ciertamente, estas dimensiones están aceptadas como un signo o indicador de calidad; admitidas como una necesidad y un reto en los cuales deben converger entre ellas 
y dichos niveles son propios de otros niveles del sistema educativo; pero buscando ser integradas en la misión y visión de las carreras universitarias.

Dentro de este marco, el objetivo de toda universidad de calidad y con filosofía de servicio público es hacer más digna la sociedad, convirtiendo a sus estudiantes en excelentes profesionales y ciudadanos cada vez más cultos y críticos. Es por ello, que el personal universitario en todos los niveles tenga presente, de manera permanente, que estos resultados se logran cuando se vive en contextos donde la búsqueda de la verdad se practica con rigor; a través de la argumentación, el diálogo y la deliberación abierta; evitando dogmatismos y fundamentalismos, en interacción social y en colaboración con otros.

De acuerdo a lo expuesto, los cambios de perspectiva en relación con la cultura docente plantean la formación universitaria no sólo en el aspecto profesional sino también como ciudadano; en este sentido, existen razones para considerar que una formación universitaria de calidad no puede separar el comportamiento ciudadano del futuro profesional.

En este sentido, el concepto actual de formación universitaria debe tener el objetivo de cohesión social, y no sólo de competitividad; el cual debe estar derivado de las investigaciones sobre el desarrollo moral y aprendizaje ético. Dichos aspectos, están relacionadas entre sí y persiguen como objetivo la construcción de ciudadanía comprometido con el bienestar social. Durante el período de formación universitaria no debe faltar rigor para favorecer actitudes que inviten a la profundización de conocimientos sobre aquellos temas que afectan a la participación y toma de decisiones de los estudiantes tanto en contextos públicos como privados; tampoco en aquellos que previsiblemente puedan afectarles como profesionales y ciudadanos en proceso de formación.

En virtud de lo planteado, es conviene predecir el cúmulo de conocimientos y competencias que necesitará el futuro profesional universitario en cualquier área del conocimiento, de forma que su participación en la toma de decisiones sea adecuada, pertinente y fundamentada, cuando sea requerido como referente. Esta tarea obliga a incorporar en la formación universitaria elementos para la reflexión, procedimientos para la praxis y una serie de actitudes y valores que faciliten su actuación en base a criterios de corrección y veracidad universitaria.

A este respecto, la carrera de contaduría pública es una profesión que conlleva un compromiso técnico, social y por ende tributario, además de, componentes analíticos que promuevan su buena función dentro de las organizaciones y la sociedad, por lo que, la formación de los futuros profesionales debe estar encaminada a una interdisciplinariedad de conocimientos que contribuyan al efectivo desarrollo de sus habilidades.

\footnotetext{
“Visión de Futuro" Año 19, Volumen N²6 N 1, Enero - Junio 2022 - Pág 1 - 21

URL de la Revista: http://visiondefuturo.fce.unam.edu.ar/index.php/visiondefuturo/index

URL del Documento: https://visiondefuturo.fce.unam.edu.ar/index.php/visiondefuturo/issue/view/22

ISSN 1668 - 8708 - Versión en Línea

E-mail: revistacientifica@fce.unam.edu.ar
} 
Ahora bien, una de las inquietudes que surge por parte del profesional contable recién egresados es que su función dentro de las organizaciones lo obliga a desempeñarse con un conocimiento arduo en los temas de interés por parte de las empresas, sin dejar de lado las responsabilidades que como ciudadano influyen en su desempeño profesional

En otras palabras, muchos han sido los trabajos de investigación consultados que están relacionados con el papel de la educación universitaria en la formación de una cultura tributaria en el contador público; sin embargo, la gran mayoría centran su atención en el profesional y no consideran otras variables que inciden directamente en la calidad de su formación, tales como: los cambios ocurridos en el currículo, la preparación que poseen los profesores para la conducción del proceso de enseñanza-aprendizaje en la Educación Superior, y el trabajo metodológico en función de la formación ciudadana del futuro profesional.

Para Coetzee y Oberholzer (2009), su principal objetivo es describir la formación que se les da los estudiantes de Contaduría Pública en Sudáfrica con fines al conocimiento fiscal cuando entran en un contrato de prácticas, adicional buscan identificar el nivel de satisfacción de los estudiantes. Estos autores concluyen que a pesar que aunque la formación académica de los contadores en su mayor parte es la adecuada, al llegar a las practicas no eran lo suficientemente capaces de realizar las tareas.

Ahora bien, el aporte que brinda a esta investigación es la necesidad que los preparadores de los programas y los educadores examinen la practicidad del contenido actual que brindan las universidades, con relación a las necesidades del mundo laboral, que sobrelleven la necesidad de conocimientos en temas tributarios, analíticos, humanísticos, técnicos, entre otros, que velen por las organizaciones y la sociedad en general.

Así mismo, el trabajo de Herrera (2014), tuvo como objetivo identificar la concepción de la cultura tributaria en las instituciones de educación superior colombianas, al igual que evaluar procedimientos y controles que pueden ser útiles para estas. Para alcanzar estos objetivos utilizó el paradigma cualitativo, que se caracteriza por la conceptualización de la gestión tributaria, como una realidad construida que se rige por leyes sociales que relacionan al Estado y a la Sociedad, concluyendo que se deben acoger estrategias para incentivar la cultura tributaria desde edades tempranas, en aras de fomentar el bien común y de alcanzar la formación de individuos responsables y comprometidos con las buenas prácticas tributarias.

Por otra parte, el trabajo de investigación de Aragonés, Lópaz, y Campos (2015), tuvo como propósito dar a conocer la poca conciencia tributaria y la baja moral que tiene la sociedad española a causa de la ausencia en la formación en las escuelas y universidades

\footnotetext{
"Visión de Futuro" Año 19, Volumen N²6 N 1, Enero - Junio 2022 - Pág 1 - 21

URL de la Revista: http://visiondefuturo.fce.unam.edu.ar/index.php/visiondefuturo/index

URL del Documento: https://visiondefuturo.fce.unam.edu.ar/index.php/visiondefuturo/issue/view/22

ISSN 1668 - 8708 - Versión en Línea

E-mail: revistacientifica@fce.unam.edu.ar
} 
sobre estos temas, concluyen que los profesores tienen un nivel alto en ética, pero se enfocan en enseñar "números", consideran que pueden proporcionar más valor ético donde alienten a los estudiantes a combatir el fraude fiscal con conciencia tributaria.

Otros autores como Aguilar, Ceballos, Restrepo y Gómez (2015) enfatizan en los modelos de formación que se requieren para que los contadores públicos cumplan con las necesidades del Estado, las organizaciones, la comunidad y las familias, empleando un método de investigación hermenéutico, en el cual concluyeron que el sistema educativo está con falencias ya que no responde acertadamente a las necesidades socioeconómicas del país, presentando vacíos a nivel profesional.

Para Silvestri y Silvestri (2015), la importancia del trabajo conjunto entre los medios institucionales, la empresa privada y las instituciones universitarias para la acción conjunta en materia de estrategias de aprendizaje de la cultura tributaria en la educación universitaria venezolana; concluyendo que son necesarios contenidos referidos a los recursos tributarios del Estado y su relación con las necesidades públicas.

Los autores Yaguache-Aguilar, Pardo-Cueva y Espejo-Jaramillo (2018), desarrollaron un trabajo cuya finalidad fue difundir las estrategias aplicadas y los logros alcanzados por la Universidad Técnica Particular de Loja (UTPL) en México y fomento de los Núcleos de Apoyo Contable y Fiscal (NAF) desde la Academia, lo cual ha generado enriquecimiento de saberes para estudiantes, docentes y funcionarios del Servicio de Rentas Internas (SRI) y especialmente de los sectores que han sido intervenidos para crear competencias en el cumplimiento de sus obligaciones tributarias.

Dichos autores, consideran necesario continuar con los Núcleos de Apoyo Contable y Fiscal (NAF), brindando asesoría tributaria de manera gratuita que permita a la ciudadanía en general conocer la importancia de los impuestos para el desarrollo del país; concluyendo que para fomentar la cultura tributaria se requiere de un trabajo conjunto entre la administración tributaria, la academia y la sociedad.

Señalan Montoya y Castañeda (2020), que en las instituciones universitarias no se percibe el conocimiento de la mejor manera, por falta de actualización de los profesores y del contenido de las materias, además de la poca práctica en la aplicabilidad de la parte tributaria y en cuanto a la comprensión de la esencia de esta que coadyuve a asimilar la norma así esta esté en un continuo cambio.

Por lo antes señalado, uno de los aspectos importantes a considerar en la formación de los futuros profesionales de la contaduría pública está representado por la educación tributaria, la cual tiene como finalidad transmitir opiniones, valores y actitudes respecto a la responsabilidad tributaria de los ciudadanos. Su objetivo no es enseñar contenidos de corte

\footnotetext{
"Visión de Futuro" Año 19, Volumen N²6 N 1, Enero - Junio 2022 - Pág 1 - 21

URL de la Revista: http://visiondefuturo.fce.unam.edu.ar/index.php/visiondefuturo/index

URL del Documento: https://visiondefuturo.fce.unam.edu.ar/index.php/visiondefuturo/issue/view/22

ISSN 1668 - 8708 - Versión en Línea

E-mail: revistacientifica@fce.unam.edu.ar
} 
académico, donde los equipos de facilitadores deben trabajarlo como un tema de responsabilidad ciudadana, dado que representa un instrumento de igualdad, oportunidades, inclusión social y conformación de capital humano con principios morales y valores éticos.

Según Solórzano, (2013), la educación tributaria debe comenzar desde los primeros niveles educativos y representa una estrategia por excelencia para la formación de una conciencia y cultura tributaria que implica asumir el cumplimiento de las obligaciones tributarias como contrapartida necesaria al legítimo ejercicio de los derechos cívicos.

Es por esta razón que, un mayor nivel de conciencia tributaria respecto al cumplimiento tributario, junto a una percepción de riesgo efectivo por su desacato, permitirá a los países disminuir los elevados índices de evasión, informalidad y contrabando existentes.

Ahora bien, el cumplimiento de las obligaciones tributarias puede ser suficiente para lograr los objetivos de la recaudación fiscal, condicionada a la percepción de riesgo que tengan los contribuyentes, y sobre todo la capacidad de fiscalización y sanción de la Administración Tributaria de los países.

Con la finalidad de poder desarrollar una moral y sentido de compromiso en el contribuyente, es necesario generar una conciencia que establezca el marco de las acciones y lineamientos a seguir, que ayuden en el progreso y proceso de su búsqueda. Así mismo, las actuaciones del gobierno deben estar sujetas sean a que sean realizadas con total transparencia y eficiencia en el manejo de los recursos públicos para incentivar a los sujetos pasivos al cumplimiento voluntario de sus obligaciones tributarias.

Para Matteucci (1995), la conciencia tributaria es la interiorización en los individuos de los deberes tributarios fijados por las leyes, para que se cumplan de manera voluntaria y a su vez que este cumplimiento genere un beneficio común para la sociedad de la cual forman parte.

En este sentido Guaiquirima (2004), asevera que la formación de la conciencia tributaria no es un trabajo fácil, requiere tiempo, ya que implica un proceso continuo de aprendizaje y asimilación por parte de la sociedad, siendo necesario el desarrollo, discernimiento y compromiso de todos y cada uno de los funcionarios de la Administración Tributaria en respaldar la gestión que se realiza.

Con este propósito es necesario desarrollar una cultura tributaria, que permita a los ciudadanos concebir las obligaciones tributarias como un deber sustantivo, acorde con los valores democráticos, lo cual no es una tarea fácil, pues requiere la convergencia de políticas de control con políticas de carácter educativo.

\footnotetext{
"Visión de Futuro" Año 19, Volumen N²6 N 1, Enero - Junio 2022 - Pág 1 - 21

URL de la Revista: http://visiondefuturo.fce.unam.edu.ar/index.php/visiondefuturo/index

URL del Documento: https://visiondefuturo.fce.unam.edu.ar/index.php/visiondefuturo/issue/view/22

ISSN 1668 - 8708 - Versión en Línea

E-mail: revistacientifica@fce.unam.edu.ar
} 
Para Gómez (2008), la cultura tributaria es el nivel de conocimiento que tienen los individuos de una sociedad acerca del sistema tributario y sus funciones. Es necesario que todos los ciudadanos de un país posean una fuerte cultura tributaria para que puedan comprender que los tributos son recursos que recauda el Estado en carácter de administrador, pero en realidad esos recursos le pertenecen a la población, por lo tanto, es obligación del Estado devolvérselos en bienes y servicios públicos.

Acerca de la cultura tributaria, Golía (2003) afirma que es el conjunto de conocimientos, valoraciones y actitudes referidas a los tributos, así como al nivel de creencia respecto de los deberes y derechos que derivan para los sujetos activos y pasivos de esa relación.

Del mismo modo, Vanegas (2016), la define como el conjunto de información y el nivel de conocimientos que en un determinado país se tiene sobre los tributos, así como el conjunto de percepciones, criterios, prácticas y actitudes que la sociedad tiene respecto a la tributación.

Igualmente, Andrade (2012), señala que la cultura tributaria es el conjunto de valores, creencias y actitudes, compartidos por una sociedad respecto a la tributación y las leyes que la rigen, lo que conduce al cumplimiento permanente de los deberes fiscales.

En consideración de los autores Díaz, Cruz y Castillo (2017), la cultura tributaria se debe entender como un conjunto de valores, conocimientos y actitudes compartidos por los miembros de una sociedad respecto a la tributación y la observancia de las leyes que la rigen, que conducen al cumplimiento permanente y voluntario de los deberes tributarios con base en la razón, la confianza y la afirmación de los valores de ética personal, respeto a la ley, responsabilidad ciudadana y solidaridad social, tanto de los contribuyentes, como de los funcionarios de las diferentes administraciones tributarias.

También, Bonilla (2014), la define como el conjunto de acciones, que buscan conseguir que la ciudadanía se convenza de la posibilidad, la necesidad y la conveniencia de una fiscalidad justa. La cultura tributaria asume el compromiso de educar a la ciudadanía en temas fiscales, que promuevan el cumplimiento de las responsabilidades del contribuyente, consciente del buen uso de los bienes públicos.

Para Gómez, Jiménez, y Martner (2017) es importante priorizar una cultura tributaria en la que se penalice efectivamente a los evasores y, además, se entienda que los ingresos tributarios constituyen la base fundamental del financiamiento de las funciones esenciales de un Estado moderno.

Manifiestan Méndez (2004) y Armas (2009) que la cultura tributaria es un conjunto de valores, conocimientos y actitudes compartidas por los miembros de una sociedad respecto

\footnotetext{
“Visión de Futuro" Año 19, Volumen N²6 N 1, Enero - Junio 2022 - Pág 1 - 21

URL de la Revista: http://visiondefuturo.fce.unam.edu.ar/index.php/visiondefuturo/index

URL del Documento: https://visiondefuturo.fce.unam.edu.ar/index.php/visiondefuturo/issue/view/22

ISSN 1668 - 8708 - Versión en Línea

E-mail: revistacientifica@fce.unam.edu.ar
} 
a la tributación y el cumplimiento de las leyes que la rigen, esto se traduce en una conducta manifestada en el cumplimiento permanente y voluntario de los deberes tributarios con base en la razón, la confianza, la afirmación de los valores de ética personal, los deberes y derechos que derivan para los sujetos activos y pasivos respeto a la ley, responsabilidad ciudadana y solidaridad social, tanto de los contribuyentes, como de los funcionarios de las diferentes administraciones tributarias, con la finalidad de crear una conciencia cívicotributaria y así evitar la evasión fiscal.

Dentro de ese marco, Cortázar (2005) alega que contenidos como la valoración social del incumplimiento tributario responden, en gran medida, a las representaciones colectivas en torno a la Administración Tributaria, al rol del Estado y su relación con los ciudadanos, por lo tanto, es preciso actuar sobre esas representaciones. En efecto, la cultura tributaria está configurada por un conjunto heterogéneo de informaciones, prácticas y acontecimientos de referencia vinculados entre sí por la forma en que se articulan alrededor de una representación dominante.

En consecuencia, se concibe que la cultura tributaria comprende un conjunto de valores, creencias o representaciones sociales que los individuos atribuyen a la acción tributaria del Estado, connotando su conducta como contribuyente dentro de la sociedad, siendo interesante a los efectos de este trabajo considerar los planteamientos de Cortázar (2005) en tanto se ajusta a considerar la misma como formativa en el ámbito educacional.

De acuerdo a lo expuesto, se puede afirmar que la cultura tributaria no significa el nivel de conocimientos que tiene una persona acerca de sus responsabilidades contributivas y su acción correspondiente; sino más bien, la cultura tributaria se encamina hacia la construcción de los impuestos a partir de la combinación de información. En este sentido, es importante que la cultura tributaria empiece desde la escuela y continúe a nivel universitario, lo cual implica una labor educativa en el buen uso de los bienes públicos.

Por consiguiente, la cultura tributaria se identifica con el cumplimiento voluntario de los deberes y obligaciones tributarios por parte del contribuyente y no con la implementación de estrategias para incrementar la recaudación de tributos y no bajo presión, por temor a las sanciones establecidas en las normas tributarias sancionatorias.

Por esta razón, esta falta de educación tributaria se ve reflejada en un bajo nivel de conciencia y cultura tributara, que hace que los ciudadanos incumplan con la normativa, aunque conozcan sus obligaciones fiscales; haciendo caso omiso y no realizando su pago.

A este respecto, algunos contribuyentes evaden el cumplimiento de sus obligaciones tributarias con el fin de sacar provecho de ese dinero no pagado, provocando a la nación un aumento en las cargas fiscales, inequidad y desequilibrio de las finanzas públicas.

\footnotetext{
"Visión de Futuro" Año 19, Volumen N²6 N 1, Enero - Junio 2022 - Pág 1 - 21

URL de la Revista: http://visiondefuturo.fce.unam.edu.ar/index.php/visiondefuturo/index

URL del Documento: https://visiondefuturo.fce.unam.edu.ar/index.php/visiondefuturo/issue/view/22

ISSN 1668 - 8708 - Versión en Línea

E-mail: revistacientifica@fce.unam.edu.ar
} 
Por lo tanto, la cultura tributaria es de contenido individual, y consiste en la creencia que tiene cada persona o miembro de un grupo social que el pago de los tributos constituye un aporte justo, imprescindible y de provecho al ser utilizado para satisfacer las necesidades de la colectividad de la cual forman parte.

Señala Gómez (2008), que la evasión fiscal es la falta de cumplimiento de las obligaciones por parte de los contribuyentes. Esa falta de cumplimiento puede derivar en pérdida efectiva del ingreso para el Tesoro Nacional; siendo que se origina de una conducta consciente y deliberada del sujeto pasivo de la relación jurídica-tributaria, siendo una situación de importancia en las legislaciones de cada país.

En este sentido, Cortázar (2005), sostiene que la lucha contra la evasión fiscal constituye en la actualidad un tema de gran importancia, en las agendas políticas de todos los países, debido a su elevado impacto en la estabilidad económica y estrategias de desarrollo, por lo que es necesario un esfuerzo por controlar el cumplimiento de las obligaciones tributarias y generar un riesgo creíble ante su incumplimiento, siendo indispensable desarrollar una cultura tributaria que permita a los ciudadanos concebir las obligaciones tributarias como un deber sustantivo.

Los autores Morales, Ruiz y Ycaza (2009), afirman que la evasión fiscal es uno de los mayores fenómenos que afecta directamente el sistema tributario de un país, la falta de pago de los impuestos, tasas y contribuciones no sólo erosiona los ingresos del Estado, sino que deteriora la estructura y economía de un país, causando un efecto dañino para la sociedad

Para Mendoza (2013), son pocas las estrategias que a nivel universitario se han establecido para fomentar el aprendizaje en materia de cultura tributaria, las cuales deben constituir ese conjunto de medios diseñados para generar conocimientos, valores y representaciones sociales que conduzcan al ciudadano a valorar como idóneo el proceso de cumplir con sus deberes tributarios en bien de la comunidad, considerando la contraprestación social del tributo, en términos de justicia e igualdad.

A tal efecto, el contexto cultural donde se forman los futuros profesionales universitarios sugiere acciones educativas que puedan converger con las de la Administración Tributaria, a fin de modificar aquellas percepciones que refuerzan el incumplimiento, consolidando así la legitimidad social de la fiscalización tributaria, representando la posibilidad de generar estrategias educativas que fomenten una cultura tributaria, lo cual es un aspecto fundamental en el logro de dichos objetivos y su impacto en el área de la formación del profesional contable.

\footnotetext{
"Visión de Futuro" Año 19, Volumen N²6 N 1, Enero - Junio 2022 - Pág 1 - 21

URL de la Revista: http://visiondefuturo.fce.unam.edu.ar/index.php/visiondefuturo/index

URL del Documento: https://visiondefuturo.fce.unam.edu.ar/index.php/visiondefuturo/issue/view/22

ISSN 1668 - 8708 - Versión en Línea

E-mail: revistacientifica@fce.unam.edu.ar
} 
Debido a esto, se hace fundamental la sistematización de los contenidos propuestos que se deben considerar en las estrategias de aprendizaje de la cultura tributaria en la educación superior, a fin de definir específicamente todos los conceptos y teorías que sean considerados como pertinentes para la formación de la población universitaria.

En virtud de ello, hablar de educación tributaria, trasciende como una nueva práctica que se orienta al desarrollo de valores, actitudes y habilidades, elementos que están destinados a estimular en los estudiantes universitarios un juicio crítico que permita alinear su relación con el Estado y con otros ciudadanos en materia fiscal en el contexto de la convivencia democrática.

De acuerdo a lo planteado, uno de los objetivos que debe perseguir la educación universitaria es crear conciencia sobre la importancia de pagar los tributos, lo cual le permite al Estado obtener los recursos para satisfacer las necesidades públicas, además de insistir en la promoción de valores éticos y morales, fundamentado en un proceso constante de comunicación que permita difundir toda la información relacionada con los tributos, y desarrollar y ejecutar estrategias educativas que permitan formar a los universitarios esa cultura del deber ciudadano.

Cabe resaltar, que el sistema educativo debe buscar un desarrollo en el individuo de un concepto de conciencia fiscal, que permita a través del reforzamiento de los aprendido en el hogar interiorice en el estudiante el cumplimiento de las obligaciones y los deberes que este tiene, en cuanto a la contribución del gasto público; y de esta forma genere una moral tributaria fuerte con valores y principios democráticos, construyendo así una cultura cívicotributaria en la sociedad.

Dicho de otra forma, la formación universitaria y la cultura tributaria están estrechamente ligadas, ya que los docentes deben buscar a través de la educación concientizar a los estudiantes sobre la importancia de contribuir con el pago de los tributos desde una óptica de justicia y equidad. La educación se presenta como el medio más poderoso para transformar la conducta y el pensar de los individuos.

Para Brasvlasky (2005), los profesionales recién egresados tienen que optar por estudios complementarios que fortalezcan sus conocimientos en los temas tributarios, ya que lo percibido durante su formación académica resulta en muchos casos de difícil aplicación en el ejercicio profesional, dando a entender que es muy diferente lo que se aprende en las instituciones de educación superior a lo que tienen que desempeñarse laboralmente, por lo que sienten vacíos tanto en conceptos como en la forma de desarrollarse.

\footnotetext{
"Visión de Futuro" Año 19, Volumen N²6 N 1, Enero - Junio 2022 - Pág 1 - 21

URL de la Revista: http://visiondefuturo.fce.unam.edu.ar/index.php/visiondefuturo/index

URL del Documento: https://visiondefuturo.fce.unam.edu.ar/index.php/visiondefuturo/issue/view/22

ISSN 1668 - 8708 - Versión en Línea

E-mail: revistacientifica@fce.unam.edu.ar
} 
Por tanto, se requiere que la población en general reciba conocimientos sobre el tema y comprenda la importancia de sus responsabilidades tributarias, como medio eficaz para que el Estado satisfaga las necesidades del colectivo, es decir, que los ciudadanos con el apoyo de los profesionales de la contaduría pública tomen conciencia de su significado, así como la necesidad de contribuir con el cumpliendo con los deberes tributarios establecidos por la constitución nacional y las leyes.

\section{CONCLUSIÓN}

A través de la formación de una cultura tributaria se pretende que los individuos de la sociedad involucrados en el proceso, tomen conciencia con relación al deber constitucional que tienen en aportar al Estado, con la finalidad que se dispongan de los recursos necesarios para que éste cumpla con el deber de garantizar a la ciudadanía servicios públicos eficaces y eficientes.

En este sentido, los futuros profesionales deben ser individuos capaces de enfrentarse a situaciones cambiantes en las organizaciones donde se desempeñen, las cuales estarán ligadas con los conocimientos tributarios adquiridos durante su formación; siempre enfocados en su buen desempeño profesional.

Por ello, las instituciones de educación superior tienen el compromiso en darle al futuro profesional las herramientas necesarias para que desarrolle competencias que le permitan fusionar la teoría con la práctica, y de esta manera tener autonomía al momento de aplicar los conocimientos adquiridos durante su formación profesional, en virtud de lo cual se deben reinventar el pensum académico con miras al mejoramiento, para abrir espacios que fortalezcan dichas destrezas.

Así mismo, son necesarios contenidos referidos a los recursos tributarios del Estado y su relación con las necesidades públicas, las nociones generales del sistema tributario, de las finanzas públicas, el papel del sistema tributario nacional, estadal y municipal con las perspectivas de la evasión y elusión tributaria desde un enfoque ético y normativo. En estos contenidos debe resaltarse el rol de la universidad en el desarrollo de una cultura tributaria y el análisis de estrategias didácticas para la educación tributaria.

Es importante destacar que, para poder lograr un desarrollo de la cultura tributaria en la educación universitaria, es esencial que los docentes sean capacitados que le ayuden en la aplicación de estrategia de enseñanzas para lograr ese objetivo; así como revertir el desconocimiento sobre las nociones básicas y específicas del sistema tributario de los países. En este sentido, la estrategia de aprendizaje de la cultura tributaria, debe apoyarse

\footnotetext{
"Visión de Futuro" Año 19, Volumen No 26 N 1, Enero - Junio 2022 - Pág 1 - 21

URL de la Revista: http://visiondefuturo.fce.unam.edu.ar/index.php/visiondefuturo/index

URL del Documento: https://visiondefuturo.fce.unam.edu.ar/index.php/visiondefuturo/issue/view/22

ISSN 1668 - 8708 - Versión en Línea

E-mail: revistacientifica@fce.unam.edu.ar
} 
en actividades de exposición tanto de docentes como estudiantes, donde se promueva la discusión de la temática tributaria.

A este respecto, para fortalecer la cultura tributaria se requiere que la población tenga conocimientos sobre el tema y comprenda la importancia del cumplimiento de sus responsabilidades tributarias; la cual debe alimentarse con información oportuna y adecuada, que promueva el pago voluntario de sus compromisos fiscales y de esta forma lograr una recaudación firme y sostenible en el mediano y largo plazos, de manera que sea posible cumplir con los deberes del Estado, principalmente la satisfacción de las necesidades de los ciudadanos.

En todo caso, la educación debe convertirse en el medio a través del cual se generen cambios en el pensamiento, sentimiento y acción de los ciudadanos, al estimular la participación corresponsable de los individuos para mejorar la calidad de vida, de donde surge la necesidad de una relación entre el sector educativo y la Administración Tributaria, la cual debe desarrollarse en forma armónica, con respeto a los principios constitucionales y una actitud apegada a valores éticos entre los actores participantes.

No obstante, el fin que debe perseguir la educación universitaria es convertir la cultura tributaria en una de las bases fundamentales de la modernización y el desarrollo de los países, cuyos principios y objetivos sean compartidos por los diversos sectores representativos de toda sociedad.

Sin duda alguna, la educación universitaria se presenta como el medio más poderoso para transformar la forma de actuar y pensar de los individuos; y debe ser uno de los temas fundamentales en la productividad y competitividad; pero resulta importante contar con una retroalimentación sobre los contenidos programáticos y la pertinencia de los programas de estudio.

Cabe destacar, que una verdadera y auténtica cultura tributaria sólo puede ser creada con conciencia, responsabilidad, transparencia y visión social que ha de nacer e instaurarse en cada uno de las dependencias de la Administración Tributaria, a través del principio de equidad, a fin de que puedan extrapolarse y asumirse como un enfoque compartido entre los diferentes actores de la relación jurídico-tributaria, asumiendo conciencia de sus deberes y responsabilidades de un modo compartido y, fundamentado en la anhelada justicia colectiva a la cual constantemente se apela.

Para tal efecto, la estrategia para fomentar la cultura tributaria debe armonizar lo ético y lo cultural, con lo cual se contribuye el fomento de la cultura de la legalidad; en este sentido, la educación desempeña un papel esencial en la enseñanza de la cultura tributaria.

\footnotetext{
"Visión de Futuro" Año 19, Volumen N²6 N 1, Enero - Junio 2022 - Pág 1 - 21

URL de la Revista: http://visiondefuturo.fce.unam.edu.ar/index.php/visiondefuturo/index

URL del Documento: https://visiondefuturo.fce.unam.edu.ar/index.php/visiondefuturo/issue/view/22

ISSN 1668 - 8708 - Versión en Línea

E-mail: revistacientifica@fce.unam.edu.ar
} 
Adicionalmente, se hace necesario convertir a las universidades en espacio de construcción de valores en los cuales los estudiantes que se están formando puedan aprovechar al máximo los recursos ofrecidos. De este modo, lograrán un avance en la construcción de matrices de valores singulares y personales, guiados por ideales de dignidad, libertad y justicia. El perfil de un buen profesional universitario debe incluir su formación como ciudadano y como persona; a pesar que la realidad demuestre lo contrario, este debe ser el ideal.

En este mismo sentido, se hace necesario realizar alianzas con otras universidades a fin de fortalecer la actualización docente, la formación académica de los estudiantes, la atención a los contribuyentes y la proyección social universitaria; lo que incide de manera positiva en la conformación de una cultura tributaria que señale la evasión fiscal como práctica nociva y que valore positivamente el cumplimiento de las obligaciones tributarias.

Dentro de ese marco, y con la finalidad de apoyar las estrategias de aprendizaje de la cultura tributaria, se requiere el concurso de los organismos del Estado relacionados con la tributación y las universidades correspondientes; apoyándose en las empresas privadas de la zona a fin de realizar intercambios en materia de tributación con las universidades, con lo cual los estudiantes tendrían la posibilidad de convivir y conocer los esfuerzos que realiza el sector privado en materia fiscal, así como los beneficios obtenidos de una ajustada gestión.

Por tal motivo, para generar cultura tributaria en los futuros profesionales, es recomendable implementar estrategias para insertar en el diseño curricular de la educación superior, asignaturas relacionadas con la tributación dando a conocer los beneficios del pago de los tributos, propiciando de esa manera conciencia tributaria, otorgándoles sentido de responsabilidad y civismo; ya que ellos serán los contribuyentes y/o asesores del futuro.

En virtud de lo planteado, es necesario establecer estrategias para el aprendizaje de la cultura tributaria en la educación universitaria, indicando la necesidad de aplicar:

- estrategias pre- instruccionales: dirigidas a preparar y alertar al estudiante en relación a lo que de aprender y como debe hacerlo (activación de conocimientos y experiencias previas pertinentes) permitiéndole ubicarse en el contexto del aprendizaje significativo,

- co-intruccionales: que apoyen los contenidos curriculares durante el proceso de aprendizaje; permitiendo cubrir funciones como: detección de la información principal; conceptualización de contenidos; delimitación de la organización, entre otros, y finalmente

\footnotetext{
"Visión de Futuro" Año 19, Volumen $N^{\circ} 26$ No 1, Enero - Junio 2022 - Pág 1 - 21

URL de la Revista: http://visiondefuturo.fce.unam.edu.ar/index.php/visiondefuturo/index

URL del Documento: https://visiondefuturo.fce.unam.edu.ar/index.php/visiondefuturo/issue/view/22

ISSN 1668 - 8708 - Versión en Línea

E-mail: revistacientifica@fce.unam.edu.ar
} 
- post-instruccionales: las cuales se presentan después del contenido que se ha de aprender y permiten al alumno formar una visión sintética, integradora e incluso crítica del material de estudio; como por ejemplo las preguntas intercaladas, resúmenes finales, mapas conceptuales, entre otros.

En las cuales los docentes logren establecer un proceso de retroalimentación con los estudiantes universitario luego de la realización de las actividades propiamente enmarcada en la educación tributaria de este sector educativo.

De igual forma, es preponderante desarrollar módulos educativos universitarios, enfocados en promover la lectura entretenida sobre tributación, así como estimular a los propios estudiantes para que propongan ideas para promover la generación de este conocimiento; que sirvan para motivar la lectura sobre temas de tributación, nuevas leyes y la prevención de la evasión tributaria.

Finalmente, uno de los objetivos que deben ser planteados en la educación tributaria a nivel universitario es romper ese círculo vicioso y hacer conciencia que la tributación no sólo es una obligación legal, sino un deber moral y ético de cada persona ante la sociedad. Además, los ciudadanos deben internalizar que cumplir con tal responsabilidad les confiere la autoridad necesaria para exigir al Estado que haga un uso correcto y transparente de los recursos públicos.

\section{REFERENCIAS}

Abreu, J. (2016). Metodología de la investigación: Preguntas. Métodos. Todo menos tesis.

Canadá: Editorial CreateSpace Independent Publishing Platform.

Aguilar, P., Ceballos, A., Restrepo, L., y Gómez, Y. (2015). La educación contable universitaria: herramientas formativas para satisfacer las necesidades de las organizaciones, el Estado, la comunidad y las familias. Revista En-Contexto /ISSN: 2346-3279, 3(3), 161-180. Recuperado a partir de https://ojs.tdea.edu.Co/index.php/ encontexto/article/view/298

Andrade, M. (2012). Cultura tributaria para una mayor recaudación fiscal. Área de investigación: Contribuciones. XVII Congreso Internacional de Contaduría, Administración e Informática. México D.F., México. (pp. 3 - 8).

Aragonés-Jericó, A. Lópaz-Pérez, C., Campos-Aparicio (2015). Tax awareness from school? The teachers approach. ICERI2015 Proceedings, pp. 3146-3153.

Armas, E., y Eizaga, M. (2009). Educación para el desarrollo de la cultura tributaria. REDHECS: Revista electrónica de Humanidades, Educación y Comunicación Social,

\footnotetext{
"Visión de Futuro" Año 19, Volumen No 26 N 1, Enero - Junio 2022 - Pág 1 - 21

URL de la Revista: http://visiondefuturo.fce.unam.edu.ar/index.php/visiondefuturo/index

URL del Documento: https://visiondefuturo.fce.unam.edu.ar/index.php/visiondefuturo/issue/view/22

ISSN 1668 - 8708 - Versión en Línea

E-mail: revistacientifica@fce.unam.edu.ar
} 
4(6), 141-160. Disponible en https://dialnet.unirioja.es/servlet/articulo? Código $=2937210$

Bonilla, E. (2014). La cultura tributaria como herramienta de política fiscal: la experiencia de Bogotá. Revista Ciudades, Estados y Política (1), 21 - 35.

Botella, J. y Sánchez-Meca, J. (2015). Meta-análisis en Ciencias Sociales y de la Salud. Madrid: Editorial Síntesis.

Brasvlasky, G. (2005). Educación y Políticas para América Latina. Publicado por la Oficina Regional de Educación para América Latina y el Caribe. UNESCO. Chile. Disponible en http://library.iated.org/view/ARAGONESJERICO2015 TAX

Coetzee, S., y Oberholzer, R. (2009). The tax knowledge of South African trainee accountants: A survey of the perceptions of training officers in public practice. Accounting Education: an international journal. Volumen 18(4-5), 421-441.

Disponible en: http://www.tandf.co.uk/journals/titles/09639284.asp

Cortázar, J. (2005). Estrategias educativas para el desarrollo de una «cultura tributaria» en América Latina. Experiencias y líneas de acción. Revista del CLAD Reforma y Democracia. (17) 99-122.

De Pelekais, C.; Finol, M.; Neuman, N. y Belloso, O. (2007). El ABC de la Investigación. Una aproximación teórico-práctica. Maracaibo: Ediciones Astro Data, S.A.

Díaz, J., Cruz, B. y Castillo, N. (2017). Cultura Tributaria. Revista Publicando, 3(9), 697-705. Recuperado a partir de https://revistapublicando.org/revista/index.php/crv/article/ view/403

Golía, J. (2003). SENIAT: Evasión Cero. Revista Dinero 180. Venezuela. Disponible en https://www.dinero.com.ve/180/portada/tributos. Consultada en fecha 02 de febrero de 2021.

Gómez, J., Jiménez, J. y Martner, R. (2017). Consensos y conflictos en la política tributaria de América Latina. Libros de la CEPAL, No. 142 (LC/PUB.2017/5-P), Santiago, Comisión Económica para América Latina y el Caribe (CEPAL)

Gómez, L. (2008). La difusión de la cultura tributaria y su influencia en el sistema educativo peruano. Tacna, Perú.

Guaiquirima, C. (2004). Cultura Aduanera y Tributaria. Temas Tributarios 2. Oficina de Divulgación Aduanera y Tributaria. Servicio Nacional Integrado de Administración Aduanera y Tributaria (SENIAT). (p.12). Caracas.

\footnotetext{
"Visión de Futuro" Año 19, Volumen $\mathrm{N}^{0} 26$ No 1, Enero - Junio 2022 - Pág 1 - 21

URL de la Revista: http://visiondefuturo.fce.unam.edu.ar/index.php/visiondefuturo/index

URL del Documento: https://visiondefuturo.fce.unam.edu.ar/index.php/visiondefuturo/issue/view/22

ISSN 1668 - 8708 - Versión en Línea

E-mail: revistacientifica@fce.unam.edu.ar
} 
Herrera, I. (2014). Hacia una concepción de gestión de la cultura tributaria en las instituciones de educación superior colombianas: un estudio de caso. Plumilla Educativa, 14(2), pp. 132-150.

Matteucci, M. (1995). La Definición de Conciencia Tributaria y los mecanismos para crearla. Revista Análisis Tributario, VIII (90), 37-38.

Méndez, M. (2004). Cultura tributaria, deberes y derechos vs. constitución de 1999. Revista Espacio Abierto, 13(1), 123-137.

Mendoza, F. (2013). La Cultura Tributaria: Competencia Esencial en el Programa Educativo de la Licenciatura en Comercio Internacional de la Universidad Estatal de Sonora. Trabajo de Grado para optar al Título de Doctor en Ciencias de lo Fiscal por el Instituto de Especialización de Ejecutivos A.C.

Mendoza, F., Palomino, R., Robles, J. y Ramírez, S. (2016) Correlación entre cultura tributaria y educación tributaria universitaria: Caso Universidad Estatal de Sonora. Revista Global de Negocios, Volumen 4(1) p. 61-76, 2016, Disponible en https://ssrn.com/abstract=2659374

Montoya, D. y Castañeda, M. (2020). Incidencia de la formación tributaria en el desarrollo profesional. Tecnológico de Antioquia Institución Universitaria. Disponible en https://dspace.tdea.edu.co/handle/tdea/713

Morales, C., Ruiz, F. y Ycaza, W. (2009). Análisis de la Evasión Fiscal en el Impuesto a la Renta del Ecuador. Recuperado de https: // www. dspace. espol. edu.ec/ bitstream/123456789/745/1/1396.pdf

Robles, J. (2002). Cultura Tributaria. Algunas pautas a seguir en su creación. Recuperado el 02 de febrero de 2021 de http://www.democraciadigital.org.

Silvestri, C. y Silvestri, K. (2015) Estrategias de aprendizaje de la cultura tributaria en la educación universitaria venezolana. Revista Formación Gerencial, Año 14.1 (93-120).

Solórzano, D. (2013). Congreso de la República. La Cultura Tributaria, un instrumento para combatir la evasión.: Disponible en: http://www2.congreso.gob.pe/sicr/cendocbib/ con4uibd.nsf/03959836C 65E2E5805257C12008IDB15/\$FILE/cultura tributaria dulio solorzano.pdf.

Vanegas, Y. (2016). Caracterización de la cultura tributaria en los estudiantes de educación básica secundaria. Caso grado noveno del Colegio Externado Nacional Camilo Torres de Colombia. Recuperado de https://ciencia.lasalle.edu.Co/contaduria publica/610

\footnotetext{
"Visión de Futuro" Año 19, Volumen No 26 No 1, Enero - Junio 2022 - Pág 1 - 21

URL de la Revista: http://visiondefuturo.fce.unam.edu.ar/index.php/visiondefuturo/index

URL del Documento: https://visiondefuturo.fce.unam.edu.ar/index.php/visiondefuturo/issue/view/22

ISSN 1668 - 8708 - Versión en Línea

E-mail: revistacientifica@fce.unam.edu.ar
} 
Velarde. C. (2006). Estrategias Educativas para el Desarrollo de una Cultura Tributaria en América Latina. Experiencias y Líneas de Acción. Revista del CLAD. Reforma y Democracia. Caracas. (17) 99-122.

Vizcaíno, A. (2001). Derecho Fiscal. 15ª Edición: Editorial Themis. México.

Yaguache-Aguilar, M., Pardo-Cueva, M., y Espejo-Jaramillo, L. (2018). Estrategias para fomentar la cultura tributaria desde la academia. Caso UTPL. Revista Killkana Social, 2(3), 145-152.

\section{RESUMEN BIBLIOGRÁFICO}

\section{William Alberto Pirela Espina}

William Alberto Pirela Espina. Especialista en Tributación graduado en La Universidad del Zulia (LUZ). Maracaibo, Estado Zulia, Venezuela. Investigador Independiente. Experiencia en el área contable, auditoría financiera y tributaria. Docente Universitario a nivel de pregrado y postgrado. Conferencista internacional. Asesor Tributario y Financiero. ORCID ID: https://orcid.org/0000-0003-3811-222X.

\footnotetext{
"Visión de Futuro" Año 19, Volumen No 26 No 1, Enero - Junio 2022 - Pág 1 - 21

URL de la Revista: http://visiondefuturo.fce.unam.edu.ar/index.php/visiondefuturo/index

URL del Documento: https://visiondefuturo.fce.unam.edu.ar/index.php/visiondefuturo/issue/view/22

ISSN 1668 - 8708 - Versión en Línea

E-mail: revistacientifica@fce.unam.edu.ar
} 